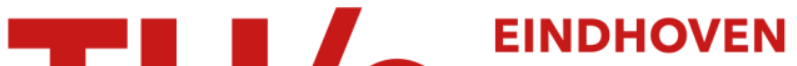 UNIVERSITY OF TECHNOLOGY
}

\section{A scalable optical packet switch with label processing for DPSK and OFDM data packets}

\section{Citation for published version (APA):}

Wang, W., Calabretta, N., Yang, H., Lee, S. C. J., Ditewig, T., De Waardt, H., \& Dorren, H. J. S. (2010). A scalable optical packet switch with label processing for DPSK and OFDM data packets. In 2010 Conference on Optical Fiber Communication, Collocated National Fiber Optic Engineers Conference, OFC/NFOEC 2010 (pp. OWI5). [5465651] Institute of Electrical and Electronics Engineers.

\section{Document status and date:}

Published: 30/06/2010

\section{Document Version:}

Publisher's PDF, also known as Version of Record (includes final page, issue and volume numbers)

\section{Please check the document version of this publication:}

- A submitted manuscript is the version of the article upon submission and before peer-review. There can be important differences between the submitted version and the official published version of record. People interested in the research are advised to contact the author for the final version of the publication, or visit the $\mathrm{DOI}$ to the publisher's website.

- The final author version and the galley proof are versions of the publication after peer review.

- The final published version features the final layout of the paper including the volume, issue and page numbers.

Link to publication

\section{General rights}

Copyright and moral rights for the publications made accessible in the public portal are retained by the authors and/or other copyright owners and it is a condition of accessing publications that users recognise and abide by the legal requirements associated with these rights.

- Users may download and print one copy of any publication from the public portal for the purpose of private study or research.

- You may not further distribute the material or use it for any profit-making activity or commercial gain

- You may freely distribute the URL identifying the publication in the public portal.

If the publication is distributed under the terms of Article 25fa of the Dutch Copyright Act, indicated by the "Taverne" license above, please follow below link for the End User Agreement:

www.tue.nl/taverne

Take down policy

If you believe that this document breaches copyright please contact us at:

openaccess@tue.nl

providing details and we will investigate your claim. 


\title{
A scalable optical packet switch with label processing for DPSK and OFDM data packets
}

\author{
W. Wang, N. Calabretta, H. Yang, S.C.J. Lee, T. Ditewig, H. de Waardt and H.J.S. Dorren \\ COBRA Research Institute, Eindhoven University of Technology, PO. Box 512, 5600MB - Eindhoven, The Netherlands \\ n.calabretta@tue.nl
}

\begin{abstract}
We present a scalable and low latency optical packet switch for DPSK and OFDM packets. Results show error-free operation of 1x64 optical packet switch for 12x10 Gb/s DPSK packets and $12 \times 40 \mathrm{~Gb} / \mathrm{s}$ OFDM packet.
\end{abstract}

(C) 2010 Optical Society of America

OCIS codes: (060.6719) Switching, packet; (200.4740) Optical processing; (130.7408) Wavelength filtering devices.

\section{Introduction}

The exponential growth of data Internet traffic will require high capacity networks capable of efficiently routing various types of data format packets. Optical packet switching networks are expected to provide the required capacity and flexibility for high-speed networks. Meanwhile, high spectral efficient modulation formats such as differential phase shift keying (DPSK), differential quadrature phase shift keying (DQPSK) and orthogonal frequency division multiplexing (OFDM) are candidates for data signals at bit-rates $>100 \mathrm{~Gb} / \mathrm{s}$. They require smaller bandwidth for transmission a given data rate, and are more robust to dispersion and nonlinear effects in the optical communication system. As a result, it is important that optical packet switches (OPS) should be able to handle transparently data packets with variable data-formats. Moreover, OPS should be capable to control a large number of ports, operate at low power and introduce low latency.

In our previous work, exploiting the parallelism in the photonic domain, we have demonstrated a scalable, low latency OPS employing in-band labeling technique and error free operation with low power penalty for $160 \mathrm{~Gb} / \mathrm{s}$ RZ-OOK was reported [1,2]. Here, we extend the concept of the OPS to demonstrate transparent switching of multiple modulation formats, such as DPSK and OFDM. We demonstrate parallel processing of 6 in-band labels which allows for addressing $2^{6}=64$ output ports. We also present results showing error-free operation for $12 \times 10$ $\mathrm{Gb} / \mathrm{s}$ DPSK multi-colored packets and 12 x $40 \mathrm{~Gb} / \mathrm{s}$ OFDM multi-wavelength packets with low penalty.

\section{Experimental set-up}

The experimental set-up is shown in Figure 1. At the transmitter side, we generate packets with two types of modulation formats. First, we generate 12 x $10 \mathrm{~Gb} / \mathrm{s}$ DPSK multi-wavelength payload by modulating 12 continuous wave (cw) - lasers with wavelengths from $1543.67 \mathrm{~nm}$ to $1548.45 \mathrm{~nm}$ by using a $\mathrm{LiNbO}_{3}$ phase modulator. The channel wavelengths are spaced by $50 \mathrm{GHz}$. Second, we generate 12 x $40 \mathrm{~Gb} / \mathrm{s}$ OFDM multi-wavelength payload by modulating $12 \mathrm{cw}$-lasers with wavelength also from $1543.67 \mathrm{~nm}$ to $1548.45 \mathrm{~nm}$ by using $10-\mathrm{GHz} \mathrm{LiNbO}_{3}$ amplitude modulator. The channel wavelengths spaced by $50 \mathrm{GHz}$ are chosen such that the wavelengths of the cw-labels are located at a zero of the spectra of the multi-wavelength packets (see Figure 2a-b). A similar strategy is chosen for the OFDM payload (see Figure 2c-d). Here, we use discrete multitone modulation (DMT), which is the baseband version of OFDM, with up to 64-state quadrature amplitude modulation (64-QAM). To optimize the bandwidth utilization, we use Chow's rate-adaptive bit-loading algorithm $[3,4]$ to maximize the achievable bit rate. Thus, we are able to transmit more than $40 \mathrm{~Gb} / \mathrm{s}$ data traffic in less than $10 \mathrm{GHz}$ bandwidth. In the experiment, a computer is used to emulate the digital DMT modulator and the data traffic is then generated by an arbitrary waveform generator

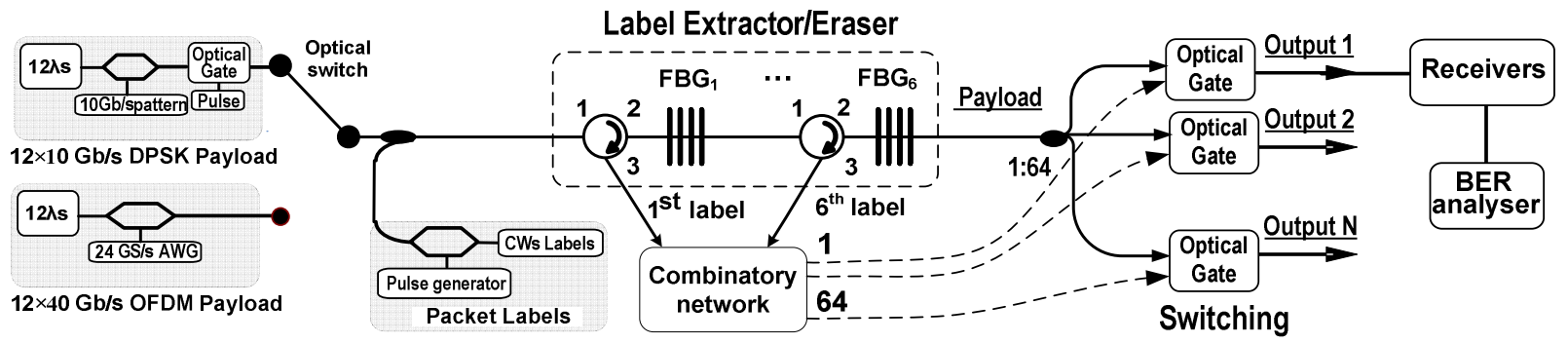

Figure 1: Experimental set-up. Two types of modulation formats are generated and processed by the optical packet switch. 


\section{OWI5.pdf}

(AWG) running at 24 GSamples/s. By using an optical gate, multi-wavelength DPSK and OFDM data packets with duration of 3.6ns and $2.8 \mathrm{~ns}$ of guard time were generated. The length of payload is limited by the pattern generator and does not form a fundamental restriction. An optical switch is used to choose between two types of format.

The address information of the packets is encoded using in-band labels with the same duration as the packet payload. Allocation of the label within the $12 \times 10 \mathrm{~GB} / \mathrm{s}$ DPSK and $12 \times 40 \mathrm{~GB} / \mathrm{s}$ OFDM is illustrated in Figs. 2a and 2c (6 labels at wavelengths $\mathrm{L}_{1}=1543.88 \mathrm{~nm}, \mathrm{~L}_{2}=1544.36 \mathrm{~nm}, \mathrm{~L}_{3}=1545.16 \mathrm{~nm}, \mathrm{~L}_{4}=1546.92 \mathrm{~nm}, \mathrm{~L}_{5}=1547.72 \mathrm{~nm}$, $\mathrm{L}_{6}=1548.2 \mathrm{~nm}$ ). The wavelengths of the labels are located at the zero's of the spectra of the multi-wavelength payloads. The in-band labelling has two advantages: firstly $\mathrm{N}$ labels allow for encoding $2^{\mathrm{N}}$ addresses which makes that a large number of ports can be addressed within the limited payload bandwidth. Secondly, the parallel and asynchronous operation of the label processing makes high speed clock recovery redundant. This is essential for reducing latency and power consumption. The labels are then coupled to the payloads.

The data packets are fed into the OPS consisting of a label extractor/eraser, a combinatory network, and transparent optical gates. The label extractor separates the labels and the payload. The label extractor consists of a cascade of narrow-bandwidth fiber Bragg Gratings (FBGs) and optical circulators. The FBGs are centered around the central wavelengths of the labels. The FBGs have a Gaussian profile with $98 \%$ of reflectivity and a $-3 \mathrm{~dB}$ bandwidth of 6 $\mathrm{GHz}$. This is essential to avoid distortions in the packet payload. Figures $2 b$ and $2 d$ show the payloads after the labels extraction. Afterwards the payload is broadcasted to the optical gates. The labels output the label extractor in parallel and are opto-electronic converted before being fed into a combinatory network. The combinatory network operates asynchronously. The combination of the asynchronous combinatory network and the parallel processing of the optical label makes complicated packet based clock-recovery and electrical serial-to-parallel conversion redundant. The combinatory network can be scaled to a larger number of labels without increasing the latency. For 6 optical labels, the combinatory network provides 64 distinct outputs, which act as control signals for driving 64 optical gates (output ports). The optical gates are transparent switches that support any data format and data-rate.

At the output of the switch, the DPSK payload is decoded by the receiver and analyzed by the bit-error rate tester. The OFDM payload is detected by a $10 \mathrm{GHz}$ photo-detector (PD). The received signal is electrically amplified and sent to a real-time oscilloscope running at a sampling rate of $50 \mathrm{GSamples/s.} \mathrm{The} \mathrm{final} \mathrm{demodulation} \mathrm{and} \mathrm{evaluation}$ is done offline by computer.

\section{Results}

Firstly, we investigate dynamic operation of the switch for 12 × $10 \mathrm{~Gb} / \mathrm{s}$ DPSK data packets. In the experiment we investigated the behavior of a 1x64 OPS by using only two optical gates and an $18 \mathrm{~dB}$ attenuator to account for the 1:64 splitting losses. Using two optical gates is sufficient to evaluate the cross-talk between the output ports as well as the switching dynamics. The right panel of Figures 2 shows the time evolution of the switching for $12 \times 10 \mathrm{~Gb} / \mathrm{s}$ DPSK data packets. Fig. 2e shows the separated payload after label extraction. Fig. 2f shows the control signal output from combinatory network. Figs. 2g-h show the switched packet at switch 1 and switch 2, respectively. The switched packet was detected and BER was measured. The results of the measurements are shown in the left panel of Fig. 3. Error-free operation was obtained with $1.1 \mathrm{~dB}$ of power penalty compared to the back-to-back payload.

Next, we investigate the performance for 12 x $40 \mathrm{~GB} / \mathrm{s}$ OFDM data packet. In the present experiment, 512 subcarriers are available for the DMT transmission, ranging from 0 to $12 \mathrm{GHz}$. The left panel of figure 4 shows the results from Chow's bit-loading algorithm. Different numbers of bits per subcarrier are allocated according to the
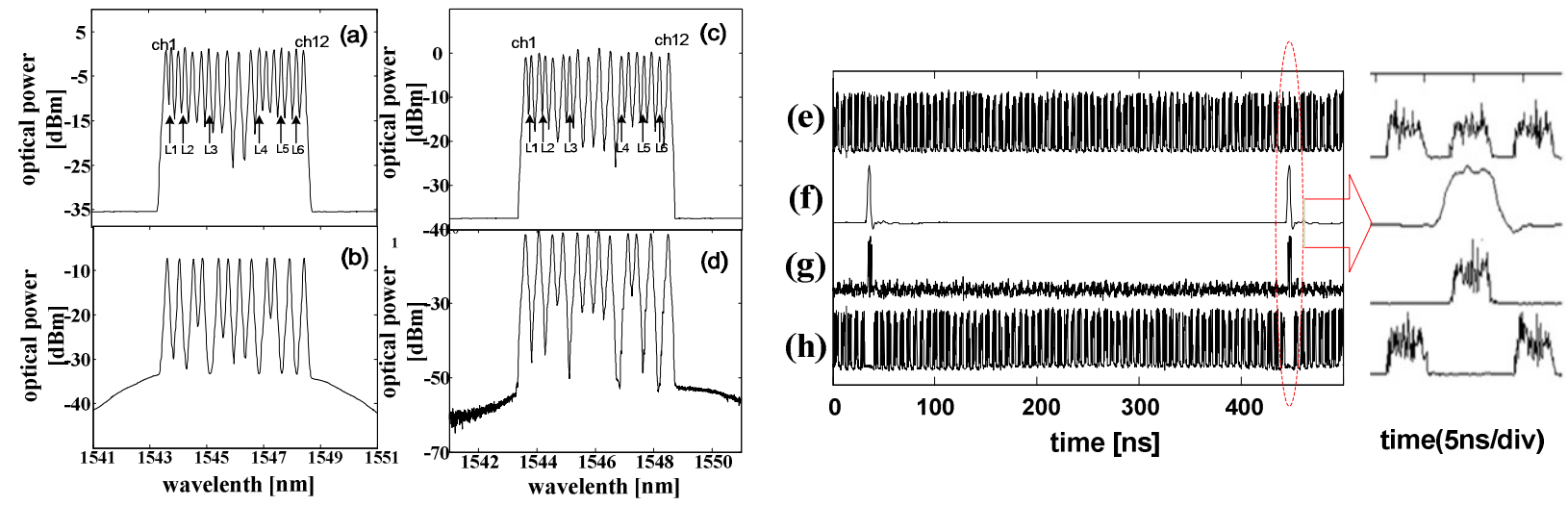

Figure 2. Spectra of the packet before and after the label extractor for a-b) $12 \times 10 \mathrm{~Gb} / \mathrm{s}$ DPSK; c-d) $12 \times 40 \mathrm{~Gb} / \mathrm{s}$ OFDM. Measured traces. e) payload after label extraction; f) Switching control generated by the combinatory network; g-h) Switched payload at output 1 and output 2 of OPS 


\section{OWI5.pdf}

(a)

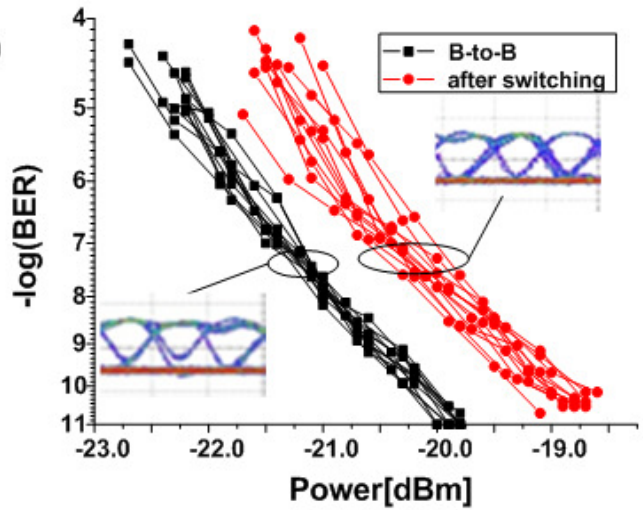

(b)

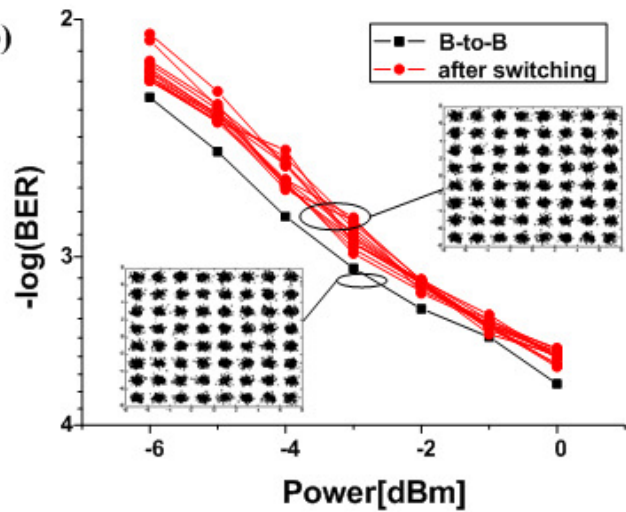

Figure 3: a) BER results and eye-diagram of $12 \times 10 \mathrm{~Gb} / \mathrm{s}$ DPSK; b) BER results and constellation diagrams of $12 \times 40 \mathrm{~GB} / \mathrm{s}$ OFDM

corresponding signal-to-noise ratio. Some of them allocated 6 bits of information at maximum (i.e. 64-QAM). Using DMT with bit-loading, finally we are able to achieve $40.3 \mathrm{~Gb} / \mathrm{s}$ bit rate.

In right panel of figure 4, we present the electrical spectra of the signal. It is shown (curve b) that the 3-dB bandwidth of the transmission system is only around $6 \mathrm{GHz}$ and the available bandwidth is not more than $12 \mathrm{GHz}$. The curve (a) in the figure is the spectrum without data modulation, which indicates the noise floor of the system. Fig. 3b shows the BER curves as a function of the received optical power. Due to the lack of a packet based BER evaluation software, the BER curves are measured under static operation by using a fixed labels that open the optical gate 1. The data stream after the gate is detected and evaluates off-line via a computer. We also get error-free operation with power penalty of $0.5 \mathrm{~dB}$ before the label extraction, and a power penalty of $0.9 \mathrm{~dB}$ after the optical gate (including $18 \mathrm{~dB}$ of splitting loss to emulate the 1:64 splitter). We also present in figure $3 \mathrm{~b}$ the constellation of the demodulated 25-30th sub-carriers (64 QAM) before and after the OPS.
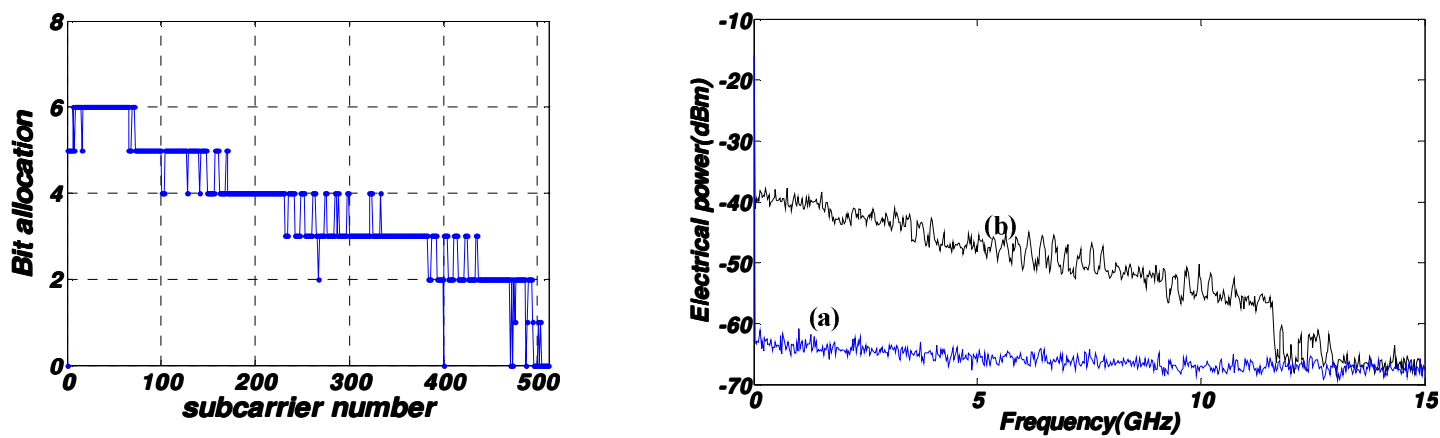

Figure 4 Left: Bit allocation map for $40 \mathrm{~Gb} / \mathrm{s}$ bit rate; Right: Electrical spectrum of the signal (a) without modulation, (b) after modulation.

\section{Discussions and conclusions}

We have demonstrated a packet switch that can transparently process multiple data-format packets with high spectral efficiency. The data packets contain in-band labels that are processed by narrow band pass filters and asynchronous electronics. The 1x64 OPS utilizes an asynchronous and scalable optical label processor for in-band labeling. The label processor employs parallel all-optical label processing in combination with an asynchronous combinatory network. This results in a latency lower than 3 ns. The dynamic switching results show error-free operation with $1.1 \mathrm{~dB}$ of power penalty for the $12 \times 10 \mathrm{~GB} / \mathrm{s}$ DPSK, and error-free operation with $0.9 \mathrm{~dB}$ of power penalty for 12 x $40 \mathrm{~GB} / \mathrm{s}$ OFDM.

\section{Acknowledgements}

This work was supported by the Netherlands Science Foundation (NWO) and Technology Foundation (STW) through the NRC Photonics and Vi programs, and Chinese Scholarship Council (200813019).

\section{References}

[1] N. Calabretta et al, 'All-Optical Label Swapping of Scalable In-Band Address Labels and 160-Gb/s Data Packets,' JLT 27, 214 - 223 (2009)

[2] W.Wang et al, 'Scalable optical packet switching at $160 \mathrm{~Gb} / \mathrm{s}$ data,' ECOC2009, Vienna, Austria, 4.6 .3 (2009)

[3] P.S. Chow et al, 'A Practical Discrete Multitone Transceiver Loading Algorithm for Data Transmission over Spectrally Shaped Channels,' IEEE Trans. Commun., 43, 773 - 775 (1995)

[4] H. Yang et al, '40-Gb/s Transmission over 100m Graded-Index Plastic Optical Fiber based on Discrete Multitone Modulation,' OFC 2009, San Diego, USA, PD 8 (2009) 